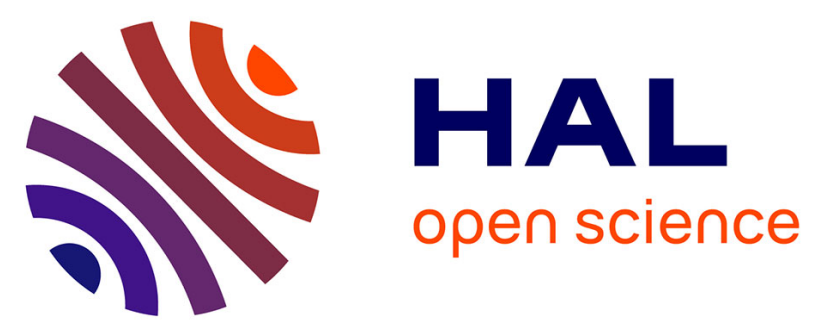

\title{
Chain Length Dependence of the Photovoltaic Properties of Monodisperse Donor-Acceptor Oligomers as Model Compounds of Polydisperse Low Band Gap Polymers
}

Cheng Zhou, Yamin Liang, Feng Liu, Chen Sun, Xuelong Huang, Zengqi Xie, Fei Huang, Jean Roncali, Thomas P. Russell, Yong Cao

\section{To cite this version:}

Cheng Zhou, Yamin Liang, Feng Liu, Chen Sun, Xuelong Huang, et al.. Chain Length Dependence of the Photovoltaic Properties of Monodisperse Donor-Acceptor Oligomers as Model Compounds of Polydisperse Low Band Gap Polymers. Advanced Functional Materials, 2014, 24 (47), pp.7538-7547. 10.1002/adfm.201401945 . hal-03344835

\section{HAL Id: hal-03344835 \\ https://univ-angers.hal.science/hal-03344835}

Submitted on 15 Sep 2021

HAL is a multi-disciplinary open access archive for the deposit and dissemination of scientific research documents, whether they are published or not. The documents may come from teaching and research institutions in France or abroad, or from public or private research centers.
L'archive ouverte pluridisciplinaire HAL, est destinée au dépôt et à la diffusion de documents scientifiques de niveau recherche, publiés ou non, émanant des établissements d'enseignement et de recherche français ou étrangers, des laboratoires publics ou privés. 


\title{
Chain Length Dependence of the Photovoltaic Properties of Monodisperse Donor-Acceptor Oligomers as Model Compounds of Polydisperse Low Band Gap Polymers
}

\author{
Cheng Zhou, Yamin Liang, Feng Liu, Chen Sun, Xuelong Huang, Zengqi Xie, \\ Fei Huang,* Jean Roncali, * Thomas P. Russell, * and Yong Cao
}

Well-defined conjugated oligomers ( $\mathrm{Sn}$ ) containing from 1 to 8 units of a tricyclic building block involving a dioctyloxybenzothiadiazole unit with two thienyl side rings (S1) are synthesized by a bottom-up approach. UV-Vis absorption data of solutions show that chain extension produces a narrowing of the HOMO-LUMO gap $(\Delta E)$ to values slightly smaller than that of the parent polymer $(\mathrm{P} 1)$. Plots of $\Delta E$ and of the band gap of films $\left(E_{\mathrm{g}}\right)$ versus the reciprocal chain length show that $\Delta E$ and $E_{\mathrm{g}}$ converge towards a limit corresponding to an effective conjugation length (ECL) of 7-8 S1 units. UV-Vis absorption and photoluminescence data of solutions and solid films show that chain extension enhances the propensity to inter-chain aggregation. This conclusion is confirmed by GIXD analyses which reveal that the edge-on orientation of short-chain systems evolves toward a face-on orientation as chain length increases while the $\pi$-stacking distance decreases beyond 7 units. The results obtained on solution-processed $\mathrm{BH}$ ) solar cells show a progressive improvement of power conversion efficiency (PCE) with chain extension; however, the convergence limit of PCE remains inferior to that obtained with the polymer. These results are discussed with regard to the role of mono/ polydispersity and chain aggregation.

\section{Introduction}

Organic photovoltaic (OPV) is a focus of considerable current interest in a general context marked by the emergence of energy and environmental concerns. ${ }^{[1]}$ OPV cells are basically developed along two main lines namely vacuum deposition of insoluble donor (D) and acceptor (A) molecules to form planar stacked D/A heterojunctions, ${ }^{[2]}$ and bulk heterojunctions (BHJ) in which donor and acceptor materials form interpenetrated segregated networks. ${ }^{[3]}$

Solution-processed bulk heterojunction (BHJ) cells combine the advantages of a larger interfacial D/A contacting area, simpler and less expensive fabrication technology and larger versatility in the choice of the substrates. In recent years, intensive multi-disciplinary research efforts has led to the synthesis of a huge number of new materials and to impressive progress in power conversion efficiency (PCE) which recently reached the symbolic ceiling of $9-10 \% \cdot{ }^{[4]}$ Soluble $\pi$-conjugated polymers combine easy processing, good film-forming capability and tunable lightharvesting and charge-transport properties; therefore, during several years, these materials have represented the only class of donor materials for BHJ cells. ${ }^{[5]}$ However, the polydispersity inherent to polymers can represent a possible source of problems regarding the reproducibility of the synthesis, purification and hence composition and electronic properties of the final active material. ${ }^{[6]}$

A possible alternative consists in the use of molecules of unequivocal chemical structure as donor material. ${ }^{[7]}$ In the past few years, this approach has generated intensive research activity and PCE of $\approx 8.0 \%$ were recently reported for solutionprocessed BHJ cells based on molecular donors. ${ }^{[8]}$ An obvious advantage of molecular donors is that they allow more reliable analyses of structure-properties relationships that remain one of the key of the design of new materials.

Well-defined $\pi$-conjugated oligomers have been widely investigated as models of the corresponding polymers. ${ }^{[9]} \mathrm{A}$ huge investment in synthetic chemistry has permitted the

DOI: 10.1002/adfm.201401945 
S1

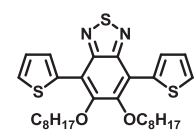

S3

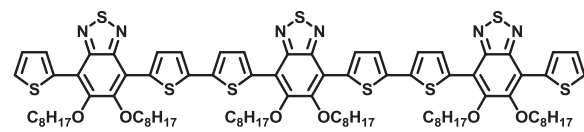

S2

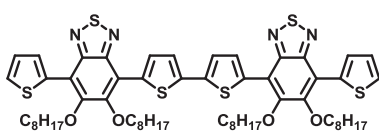

S4

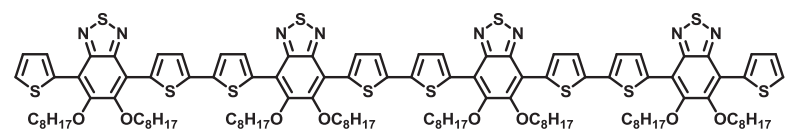

S5

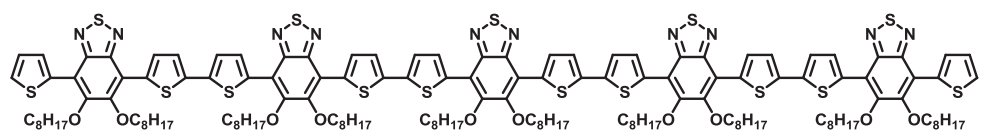

S6

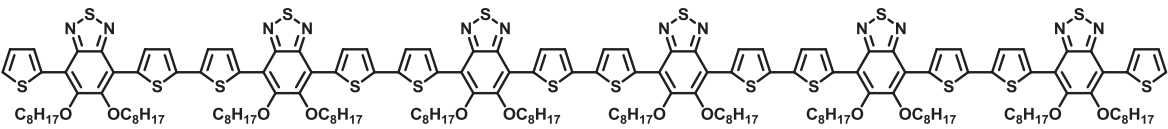

S7

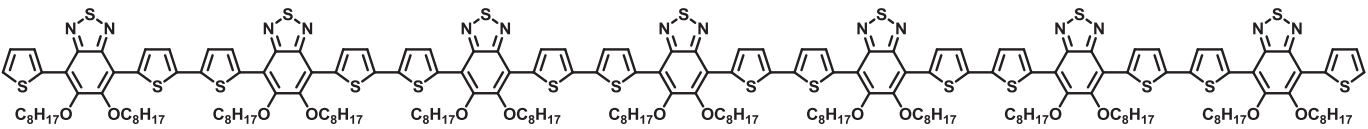

S8

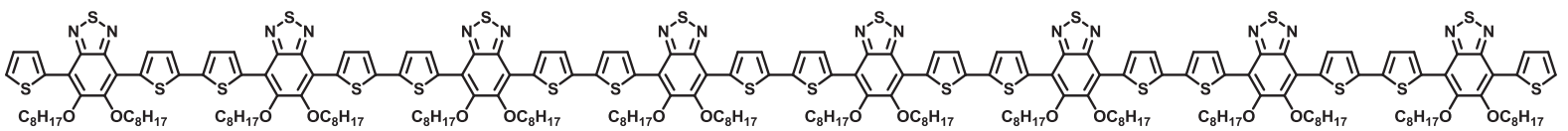

Scheme 1. Structure of oligomers S1-S8.

analysis the chain-length dependence of the electronic properties of many classes of $\pi$-conjugated systems such as, for example, oligo-phenylenes, ${ }^{[10]}$-phenylenevinylenes, ${ }^{[11]}$-thiophenes, ${ }^{[12-14]}$-thienylenevinylenes, ${ }^{[15]}$ or -fluorenes, ${ }^{[16,17]}$ and thus to significantly progress in the understanding of structure-properties relationships. These previously reported oligomers have focused primarily on homopolymers with electron-rich (donor (D)) units. However, low band gap polymers based on combination of D and A units are the most widely investigated and most efficient polymeric donor materials for OPV. ${ }^{[18]}$ Hence, well-defined oligomers combining D and A blocks are desirable for the analysis of structure-properties relationships in low band gap D-A polymers. ${ }^{[19]}$ Furthermore, the understanding of the differences in the properties of oligomers and their polymeric counterparts and finding the bridge that connects small molecules to polymers represent important topics in materials based on conjugated systems and can strongly contribute to a rational design of high performance OPV materials. ${ }^{[20]}$

In this context, we report here on the synthesis and characterization of a series of well-defined oligomers involving one (S1) to eight (S8) units of the D-A-D 5,6-bis(octyloxy)-4,7di(thiophen-2-yl)[c][1,2,5]thiadiazole basic structure (Scheme 1). The chain-length dependence of the thermal, optical, electrochemical and structural properties of S1-S8 have been investigated in solution and on thin solid films with reference to two different fractions of the parent low band gap polymer (P1 and P2). These various materials have been used as donor material for the fabrication of solution-processed $\mathrm{BHJ}$ cells with $[6,6]$-phenyl- $\mathrm{C}_{71}$-butyric acid methyl ester $\left(\mathrm{PC}_{71} \mathrm{BM}\right)$ as electron acceptor and the obtained results are discussed in terms of structure-properties relationships.

\section{Results and Discussion}

\subsection{Synthesis}

Compound $\mathbf{S 1}$ was obtained using a known procedure. ${ }^{[21]}$ Oligomers S2-S8 have been synthesized by various combinations of bromination and Stille coupling reactions (Scheme 2). The mono- and di-stannylated Stille reagents Sn-S1, dSn-S1, and $\mathbf{d S n - S 2}$ are prepared by treatment of $\mathbf{S} 1$ or $\mathbf{S} 2$ with LDA and tributyl- or trimethyl-tin chloride and used without further purification. The bromo compounds Br-S1, dBr-S1, Br-S2, $\mathrm{dBr}-\mathrm{S} 2$, and Br-S3 were obtained by reaction of NBS or Stille coupling with the appropriate oligomer. Oligomers were purified by Soxhlet extraction, column chromatography on silica gel and recycling preparative HPLC. The chemical structures were confirmed by NMR spectrometry and MALDI-TOF-MS (Figure 1, and Supporting Information). Representative ${ }^{1} \mathrm{H}$ NMR spectra of S2 and S4 are shown in Figure 1a. The ratio of integration of internal thiophene protons $\left(\mathrm{H}_{4}, \mathrm{H}_{5}\right)$ and aliphatic protons increases regularly with chain length. However, ${ }^{1} \mathrm{HNMR}$ signals become rounded for the longer systems due to their strong aggregation in deuterated chloroform. Although ${ }^{13} \mathrm{C}$ NMR spectra of S5-S8 were difficult to obtain, MALDI-TOFMS and NMR data clearly confirm that the oligomers were successfully synthesized. The small peaks in MALDI-TOF-MS spectra are mainly caused by the dissociation of alkyl chains $\left(-\mathrm{C}_{8} \mathrm{H}_{17}, 113 \mathrm{~m} / \mathrm{z}\right)$.

The thermal properties of the oligomers and polymers have been characterized by differential scanning calorimetry (DSC). DSC curves show clear melting and crystallization at temperatures that increase with chain length (Figure 2 and Table S1, $\mathrm{SI})$. Compound $\mathbf{S} 1$ is a viscous liquid at room temperature 


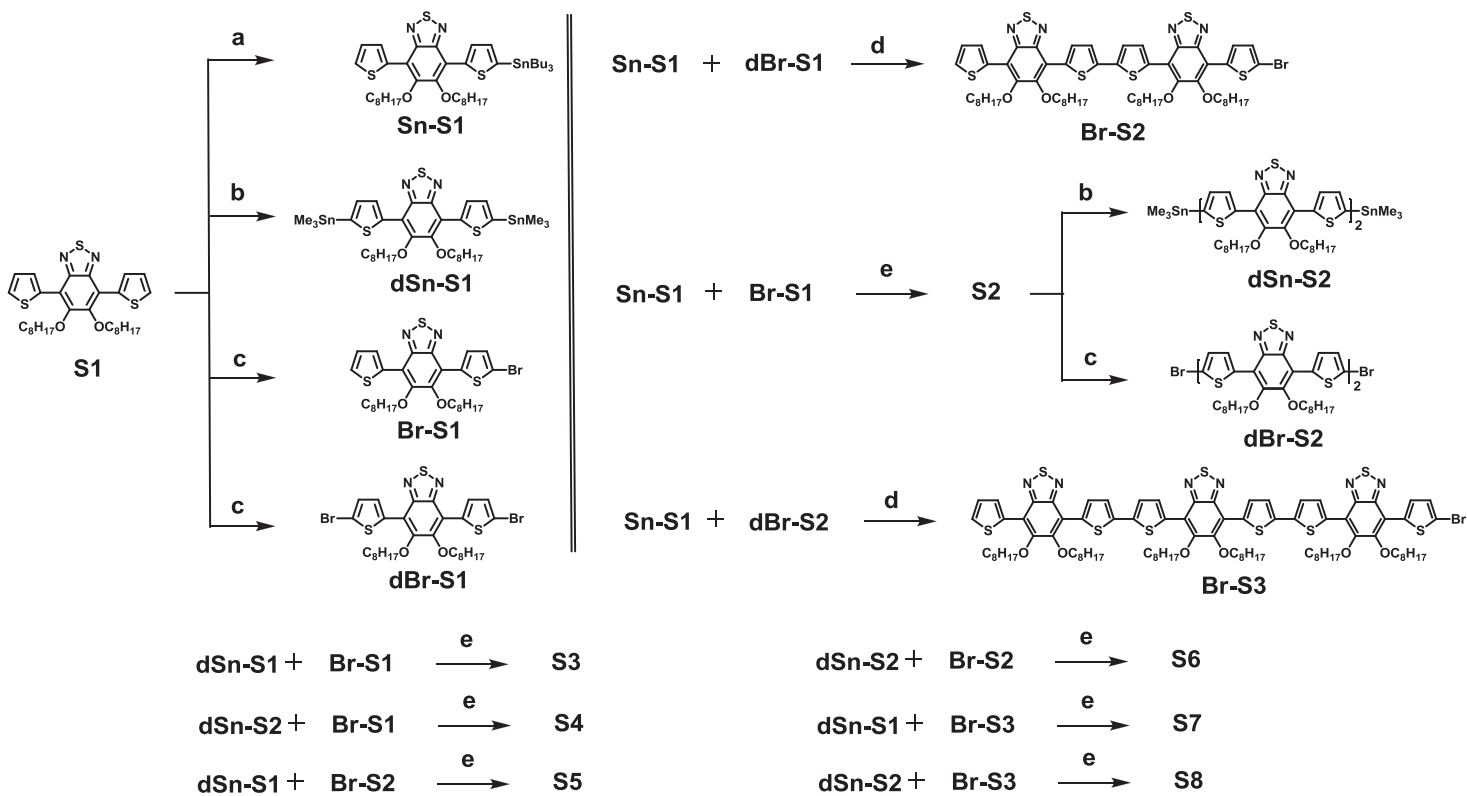

Scheme 2. Synthesis of the oligomers a) LDA, $\mathrm{Bu}_{3} \mathrm{SnCl}$; b) LDA, $\mathrm{Me}_{3} \mathrm{SnCl}$; $) \mathrm{NBS}$; d) $\left.\mathrm{Pd}\left(\mathrm{PPh}_{3}\right)_{2} \mathrm{Cl}_{2} ; \mathrm{e}\right) \mathrm{Pd}\left(\mathrm{PPh}_{3}\right)_{4}$.

while compound $\mathbf{S} 2$ shows multiple melting points possibly associated with phase transitions.

The corresponding reference polymers have been synthesized by microwave-assisted Stille coupling of 4,7-dibromo-5,6-bis(octyloxy)benzo[c][1,2,5]thiadiazole and 5,5'-bis(trimethylstannyl)-2,2'-bithiophene. The use of different molar ratios of the two reagents (i.e., 1.1:1.0 and 1.2:1.0, Scheme 3) leads to two samples of polymers P1 and P2 with different molecular weights (MW) and polydispersity index (PDI). ${ }^{[22]}$ It is noteworthy that the MW of these polymers can be well controlled by using a slight excess of one of the reagents whereas a 1.0:1.0 molar ratio leads to an almost insoluble material.

\subsection{Optical Properties}

Figure 3 shows the UV-Vis absorption spectra of the oligomers S1-S8 and polymers P1-2 in chloroform solution and as thin films while the data for the complete series are listed

(a)

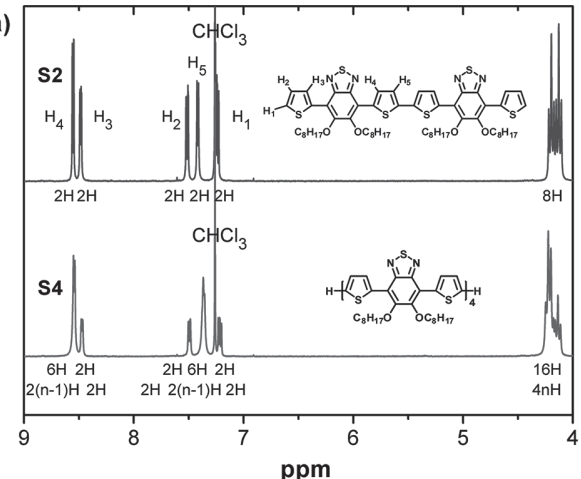

in Table 1. As expected, chain extension leads to a progressive bathochromic shift of the absorption maximum $\left(\lambda_{\max }\right)$ with an increase of the molecular absorption coefficient $(\varepsilon)$ and decrease of the HOMO-LUMO gap $\Delta E$. The solution spectra of the longest oligomers $\mathbf{S 7}$ and $\mathbf{S} 8$ shows the emergence of a shoulder around $660 \mathrm{~nm}$. Such a feature which is also clearly apparent in the spectra of the two polymers $\mathbf{P 1}$ and $\mathbf{P 2}$, can be attributed to the aggregation of the conjugated chains in solution. This attribution is further supported by the decrease of the intensity of the "aggregation shoulder" in the spectra recorded at higher temperature $\left(60^{\circ} \mathrm{C}\right.$ ) (Figure S3, SI). Interestingly, no aggregation was observed in solutions of oligomers of di-dodecyl-quaterthiophene of similar maximum length (24 aromatic rings). ${ }^{[14]}$ The faster chain aggregation of $\mathbf{S n}$ can be attributed to donor-acceptor interactions between $\mathrm{D}$ and A blocks of adjacent chains which results in stronger interchain interactions. It is interesting to observe that the intensity of the aggregation shoulder of S8, P1 and P2, correlates well with the MW of the three materials. The spectra $\mathbf{P 1}$ and $\mathbf{P} 2$ present larger absorption bands than S8 with a full width at half (b)

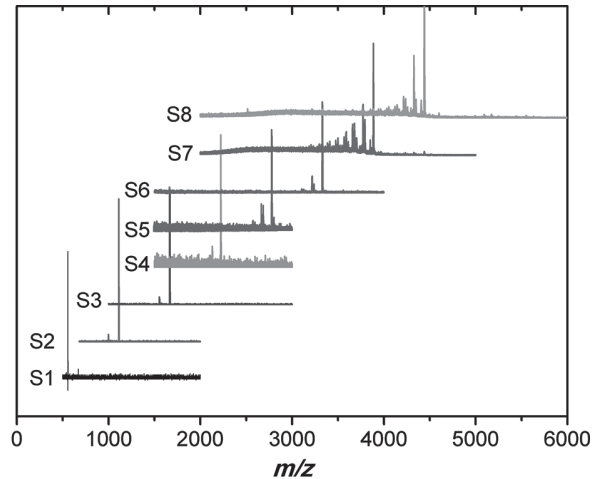

Figure 1. a) ${ }^{1}$ H NMR spectra of oligomers S2 and S4 in deuterated chloroform; b) MALDI-TOF-MS spectra of S1-S8 using terthiophene as the matrix. 

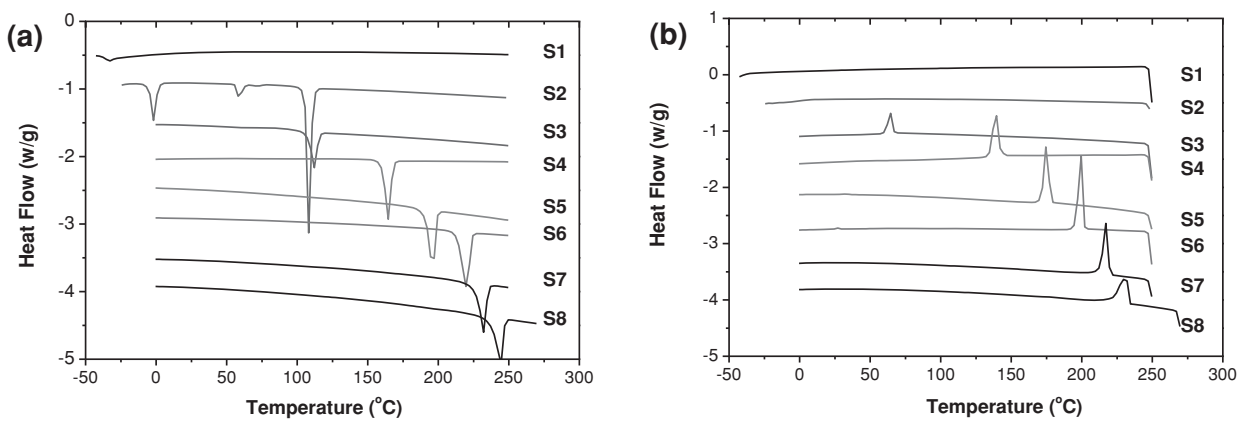

Figure 2. a) Heating and b) cooling DSC traces of the oligomers.

maximum (FWHM) increasing from $150 \mathrm{~nm}$ for $\mathbf{S} 8$ to 173 and $193 \mathrm{~nm}$ for P2 and P1 respectively. This difference reflects the presence of different lengths of conjugated segments in the polydisperse polymers, in agreement with the GPC traces (Figure S2, SI). On the other hand, comparison of the spectra of the two polymers shows that the spectrum of $\mathbf{P} 1$ is broader in agreement with the higher PDI of 2.6 vs 2.4 for P2, while the aggregation shoulder is more intense.

As shown in Table 1, the absorption spectra of films of the oligomers and polymers present a red-shift of $\lambda_{\max }$ compared to the solution. This phenomenon observed for many $\pi$-conjugated systems is generally interpreted as a signature of $J$-aggregates in the solid although some enhancement of the planarity of the structure induced by inter-chain packing in the solid can also play a role. ${ }^{[23]}$ It is noteworthy that the $\lambda_{\max }$ of the longest oligomer $\mathbf{S} 8$ in chloroform is red-shifted by $23 \mathrm{~nm}$ compared to $\mathbf{P 2}$ and $11 \mathrm{~nm}$ compared to $\mathbf{P} 1$. This result shows that extended well-defined oligomers can reach effective conjugation length (ECL) longer than that of the parent polydisperse polymer. This result provides a first indication for an ECL of the polymer comprised between 7 and 8 S1 units. Finally comparison of the energy gap values in Table 1 shows that $E_{\mathrm{g}}$ converges faster than $\Delta E$ which indicates that chain aggregation provides a determining contribution to the width of the band gap.

Extrapolations to an infinite chain-length of plots of quantities such as $\lambda_{\max }$, HOMO-LUMO gap $(\Delta E)$, band gap $\left(E_{\mathrm{g}}\right)$, or oxidation potential $\left(E_{\mathrm{ox}}\right)$ versus the reciprocal chain length have been widely used to predict the properties of infinite defect-free polymer chains. ${ }^{[17]}$ These investigations have shown that chain extension leads to a decrease of $\Delta E$ which converges towards a limiting value that should in principle, correspond to that of the polymer. The absolute value of $\Delta E$ and the rate at which it converges to the limit, or in other words the minimal chain length needed to reach this limit depends on structural factors such as bond-length alternation, planarity, aromaticity, as well as on the presence of donor and/or acceptor substituents. ${ }^{[24]}$ This chain length thus represents the intrinsic ECL of the system.

Figure 4a shows a plot of the $\lambda_{\max }$ of S1-S7 in solution and as solid films versus chain-length expressed by the number of repetitive units in the conjugated system $(n)$. The two curves show a parallel evolution with a progressive attenuation of the red shift of $\lambda_{\max }$ upon incremental chain extension. For both series the convergence limit suggests an ECL of $n=7-8$ for the polymer. The band gap $\left(E_{\mathrm{g}}\right)$ of the oligomers and polymers has been determined from the onset of absorption of the films (Table 1). Plots of $\Delta E$ and $E_{\mathrm{g}}$ versus $1 / n$ (Figure $4 \mathrm{~b}$ ) shows a linear dependence for the shorter terms with a deviation

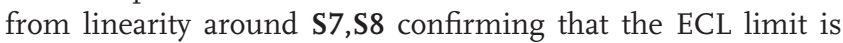
reached and that the limiting value of the band gap is equal to that of $\mathbf{S} 8$ namely $\approx 1.70 \mathrm{eV}$. Extrapolation of $\Delta E$ and $E_{\mathrm{g}}$ to infinite chain length would suggest limiting values of 2.07 and $1.58 \mathrm{eV}$ respectively this difference confirms that care should be observed in the use of extrapolations for predicting the limiting properties of infinite polymer chains. ${ }^{[13]}$ On the other hand, it can be noticed that the slope of $E_{\mathrm{g}}$ versus $1 / n$ is higher than for $\Delta E$ versus $1 / n$. This difference reflects the contribution of chain aggregation in the convergence of the energy gap in the solid state.

Figure 5a shows the photoluminescence spectra of $\mathbf{S 1 - S 8}$. As expected the emission maximum shifts bathochromically with chain extension and converges towards a constant wavelength of $\approx 630 \mathrm{~nm}$ for $\mathbf{S} 8$ similar to that of $\mathbf{P 1}$ and $\mathbf{P 2}$. The progressive emergence of a shoulder on the long wavelength side of spectrum as chain length increases is attributed to the emission
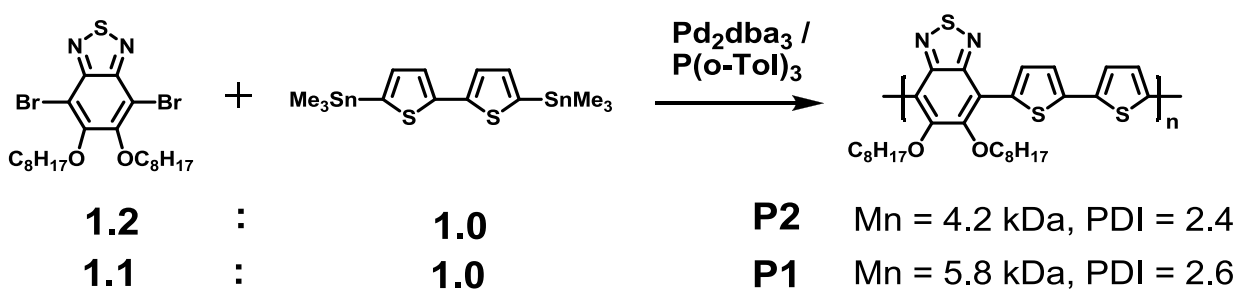

Scheme 3. Synthesis of the polymers P1 and P2. The MW and PDI were determined by a PL-GPC 220 in 1,2,4-trichlorobenzene at $150{ }^{\circ} \mathrm{C}$ with linear polystyrene as reference and gave $\mathrm{Mn}=4.2$ and $5.8 \mathrm{kDA}$ for $\mathbf{P 2}$ and $\mathbf{P 1}$ respectively. It is worth noting that the MW of the longest oligomer S8 (4.4 kDA) is comprised between these two values (Figure S2, SI). 

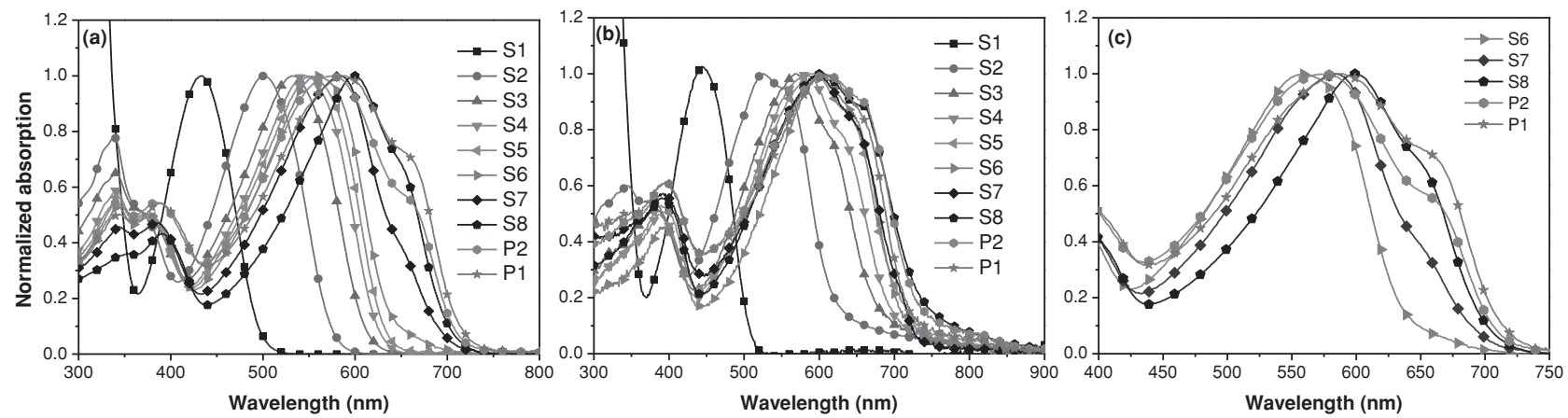

Figure 3. UV-Vis. absorption spectra of oligomers and polymers a) in $\mathrm{CHCl}_{3}$, b) in film, c) in $\mathrm{CHCl}_{3}$.

of aggregated species. The spectra recorded at ambient temperature show that for $\mathbf{S} 8$ and the polymers, the spectrum exhibits an intense peak at $\approx 700 \mathrm{~nm}$ indicating that emission of aggregates is predominant and possibly enhanced by Förster energy transfer from excitons of isolated chains to aggregates. ${ }^{[25]}$ Heating the solution to $60^{\circ} \mathrm{C}$ leads to an increase of the intrinsic emission of single chains due to the dissociation of aggregates (Figure $5 \mathrm{~b}$ ). Again, it can be noticed that despite a MW higher than that of P2, S8 aggregates dissociate more easily.

\subsection{Cyclic Voltammetry}

Cyclic voltammetry (CV) was performed in acetonitrile with tetrabutylammonium hexafluorophosphate as the supporting electrolyte. Due to the difficulty to obtain well-defined CV in methylene chloride or acetonitrile solutions, the oxidation potentials $\left(E_{\mathrm{ox}}\right)$ were estimated using the onset of oxidation wave of thin films deposited on platinum electrodes from chloroform solutions. (Figure S5, SI). Table 1 shows that as expected, chain extension leads to a gradual decrease of $E_{\mathrm{Ox}}$ which converges to a value of $\approx 0.20 \mathrm{~V}$ for S5,S6 (Figure 6). These $E_{\text {ox }}$ values lead to estimated levels of the valence band levels $\left(E_{\mathrm{vb}}\right)$ decreasing from $-5.55 \mathrm{eV}$ for $\mathbf{S} 1$ to $\approx-5.00 \mathrm{eV}$ for S6-S8 and the polymers. This faster convergence of the band gap compared to $\Delta E$, can be related to decrease of the oxidation potential of isolated oligomer chains due to interchain interactions in the solid-state. ${ }^{[26]}$

\subsection{Structural Investigations}

The chain packing in thin films of the oligomers and polymers has been characterized by grazing incidence X-ray diffraction (GIXD). ${ }^{[27]}$ Figure 7 shows the 2-D diffractograms of thin films spun-cast from chloroform solution. The S2 image shows strong, diffraction peaks indicative of high crystallinity. The diffraction peaks were recorded in the out-of-plane (OOP) direction, to probe the structure order of the materials normal to the substrate. A q value of $0.33 \AA^{-1}$ recorded for the S2 OOP peak, corresponds to a spacing of $1.9 \mathrm{~nm}$. This spacing is assigned to the (100) spacing (inter-lamellae spacing) of $\mathbf{S} 2$ suggesting that the molecule adopts an edge-on orientation on the substrate. The longer oligomers show reduced crystallinity. All diffractograms display a diffraction ring around $0.2 \AA^{-1}$ assigned to the (100) spacing. Another ring around $1.5-1.6 \AA^{-1}$ is attributed to the $\pi-\pi$ stacking. The azimuthal distribution of these diffraction rings indicates a weak orientation of the crystallites inside the film. This model suggests that whereas S2 adopts an edgeon orientation with a high crystallinity, chain extension (S3-S5) leads to more a disordered and amorphous material. For S6-S8,

Table 1. UV-Vis absorption and cyclic voltammetric data for the oligomers and polymers.

\begin{tabular}{|c|c|c|c|c|c|c|c|}
\hline Compd & $\begin{array}{l}\lambda_{\max } \\
{[\mathrm{nm}]}\end{array}$ & $\begin{array}{c}\varepsilon_{\max } \\
{\left[\mathrm{M}^{-1} \mathrm{~cm}^{-1}\right]}\end{array}$ & $\begin{array}{c}\lambda_{\max , \text { flim }} \\
{[\mathrm{nm}]}\end{array}$ & $\begin{array}{c}\Delta E \\
{[\mathrm{eV}]}\end{array}$ & $\begin{array}{l}E_{\mathrm{g}}^{\mathrm{a})} \\
{[\mathrm{eV}]}\end{array}$ & $\begin{array}{l}\left.E_{\mathrm{ox}}{ }^{\mathrm{b}}\right) \\
{[\mathrm{V}]}\end{array}$ & $\begin{array}{l}E_{\mathrm{vb}}{ }^{\mathrm{c}} \\
{[\mathrm{eV}]}\end{array}$ \\
\hline S1 & 432 & 9880 & 444 & 2.87 & 2.46 & 0.75 & -5.55 \\
\hline S2 & 501 & 46400 & 527 & 2.48 & 1.98 & 0.49 & -5.29 \\
\hline S3 & 532 & 86100 & 569 & 2.33 & 1.85 & 0.35 & -5.15 \\
\hline S4 & 546 & 104800 & 582 & 2.27 & 1.79 & 0.27 & -5.07 \\
\hline S5 & 553 & 126000 & 592 & 2.24 & 1.75 & 0.21 & -5.01 \\
\hline S6 & 560 & 166200 & 606 & 2.21 & 1.74 & 0.19 & -4.99 \\
\hline S7 & 569 & 181300 & 599 & 2.18 & 1.72 & 0.20 & -5.00 \\
\hline 58 & 599 & 220800 & 603 & 2.07 & 1.69 & 0.19 & -4.99 \\
\hline P2 & 576 & $22300^{d)}$ & 609 & 2.15 & 1.71 & 0.19 & -4.99 \\
\hline P1 & 588 & $21700^{d)}$ & 609 & 2.11 & 1.73 & 0.18 & -4.98 \\
\hline
\end{tabular}

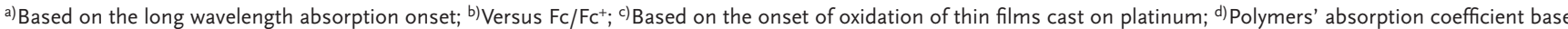
on single repeat unit. 

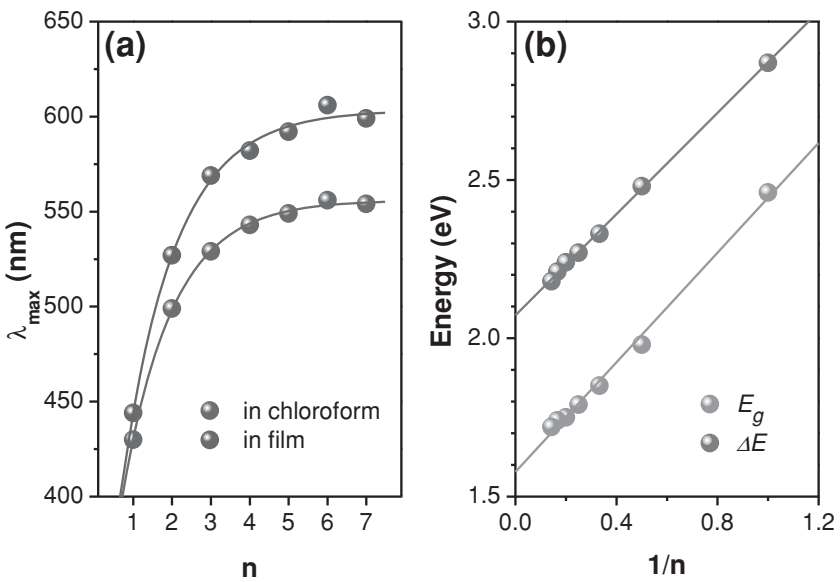

Figure 4. a) Variation of the absorption maximum of oligomers S1-S7 versus chain length. b) Plot of $\Delta E$ top and $E_{\mathrm{g}}$ vs reciprocal chain length for S1-S7.

the chain adopts a preferential face-on orientation. For the polymers, a clear enhancement of $\pi-\pi$ stacking in OOP direction is seen, and the peak area of $\mathbf{P 1}$ is more pronounced than $\mathbf{P 2}$. As already mentioned the MW of $\mathbf{S} 8$ is of the same range of P2 (Figure S2). The induced face-on orientation could be due

(a)

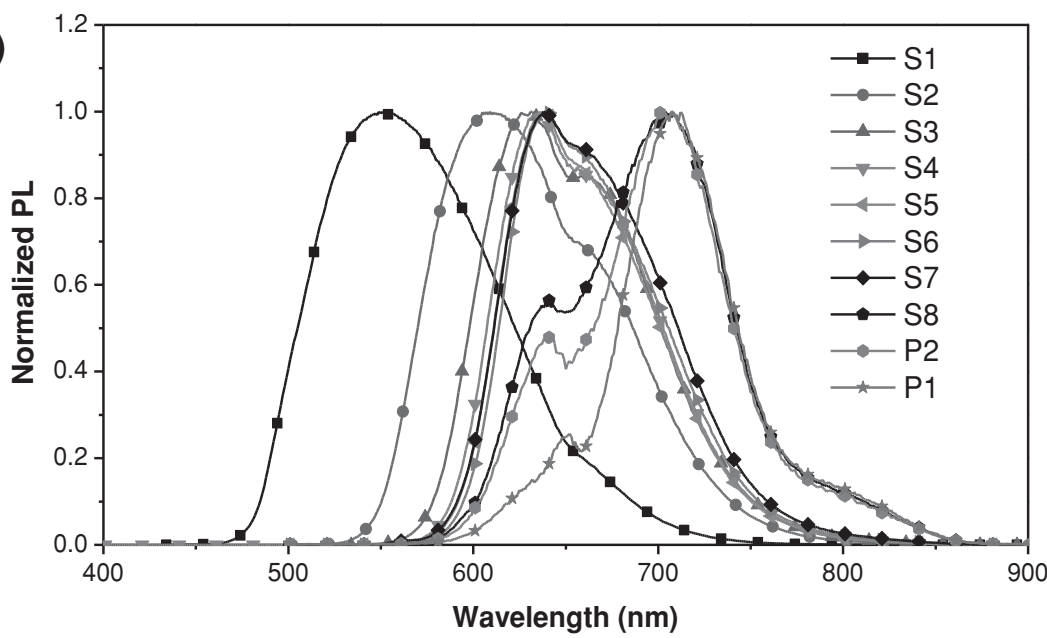

(b)

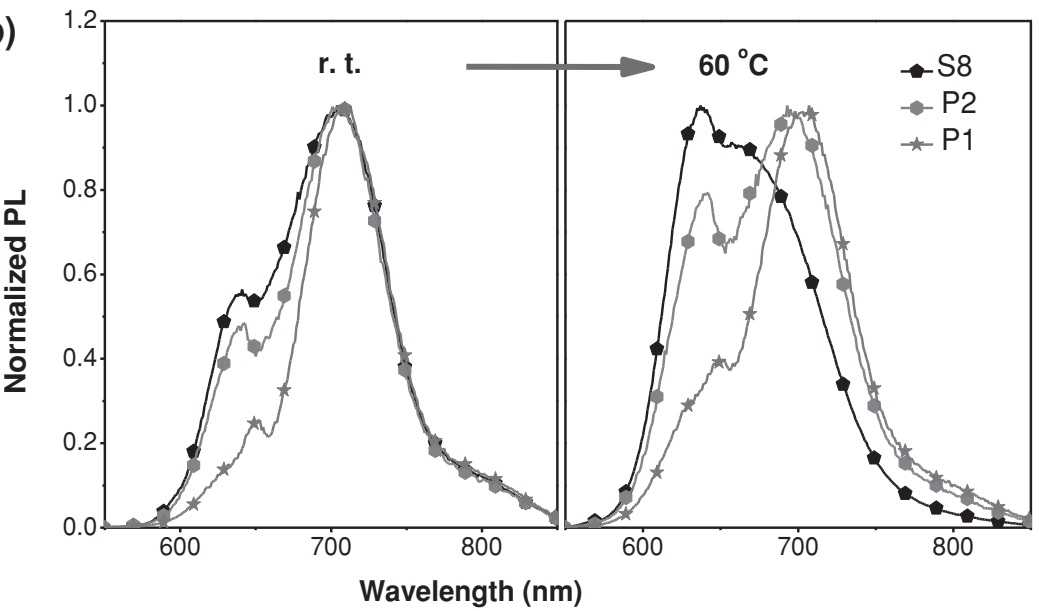

Figure 5. Photoluminescence spectra of the oligomers and polymers in chloroform: a) at room temperature; b) $\mathbf{S 8}, \mathbf{P 1}, \mathbf{P 2}$ heated to $60^{\circ} \mathrm{C}$.

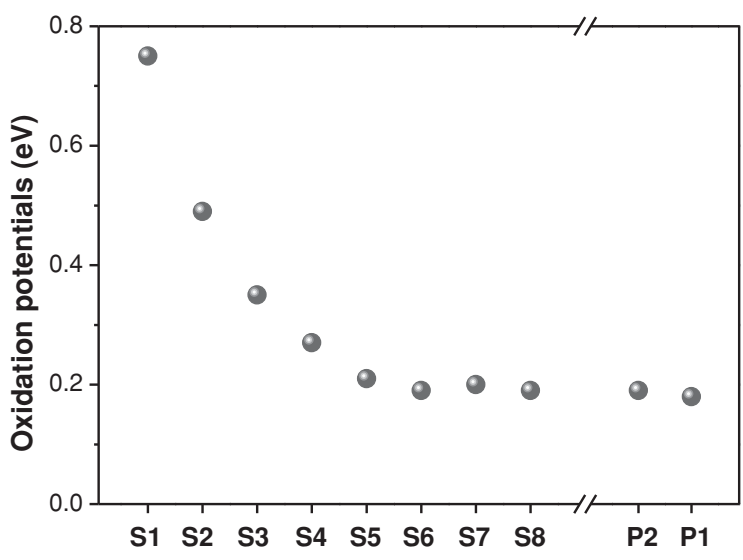

Figure 6. Evolution of the oxidation potential versus chain length.

to the larger MW component of the polymer that would act as template for the packing organization. The line-cut profiles in OOP direction are summarized in Figure 8 in which information related to the diffraction peaks are fitted and summarized. Figure 8a, shows that the (100) spacing is around $30 \AA$ for S3, and gradually decreases to $26 \AA$ for $\mathbf{S 7}$ (the S5 sample show a very weak crystalline peak, thus fitting could induce more error). The $\mathrm{d}$ spacing increases when going to higher MW. The parabola-shaped change in $\mathrm{d}$ spacing suggests a possible transition in packing in the materials. The peak area can be used to estimate the relative crystallinity of the films. For (100) peaks, there is no obvious trend for the oligomer series while a small enhancement is seen for the polymer. The crystal size in the (100) direction is in the $\approx 10 \mathrm{~nm}$ range, except for the $\mathbf{S} 5$ and $\mathbf{S 7}$ samples. The $\mathrm{d}$ spacing of $\pi-\pi$ stacking peaks shows a plateau from $\mathbf{S} 2$ to $\mathbf{S 7}$ (with a spacing $\approx 4.1 \AA$ ), and dropped to $3.75 \AA$ for P1. Although the trend is different from (100) stacking, a turning point at $\mathbf{S 7}$ is observed. It was also found that the relative crystallinity and crystal size start to increase from S7. These results confirm, in agreement with optical and electrochemical data that $\mathbf{S 7}$ which corresponds to the ECL of the system, represents a transition point where the properties of oligomers turn towards more polymer-like properties. In fact such a morphological transition around the ECL was recently observed for oligothiophenes. ${ }^{[14]}$

Figure 9 and Figure S7 show the crystallographic structure of a single-crystal of $\mathbf{S 2}$. Dihedral angles of $25.50^{\circ}$ and $16.56^{\circ}$ are found between the thiophenes and benzothiadiazole rings. The internal thiophenes adopt a coplanar anti conformation and the sulfur atoms of the thiophene rings point to the opposite direction to the thiadiazole 

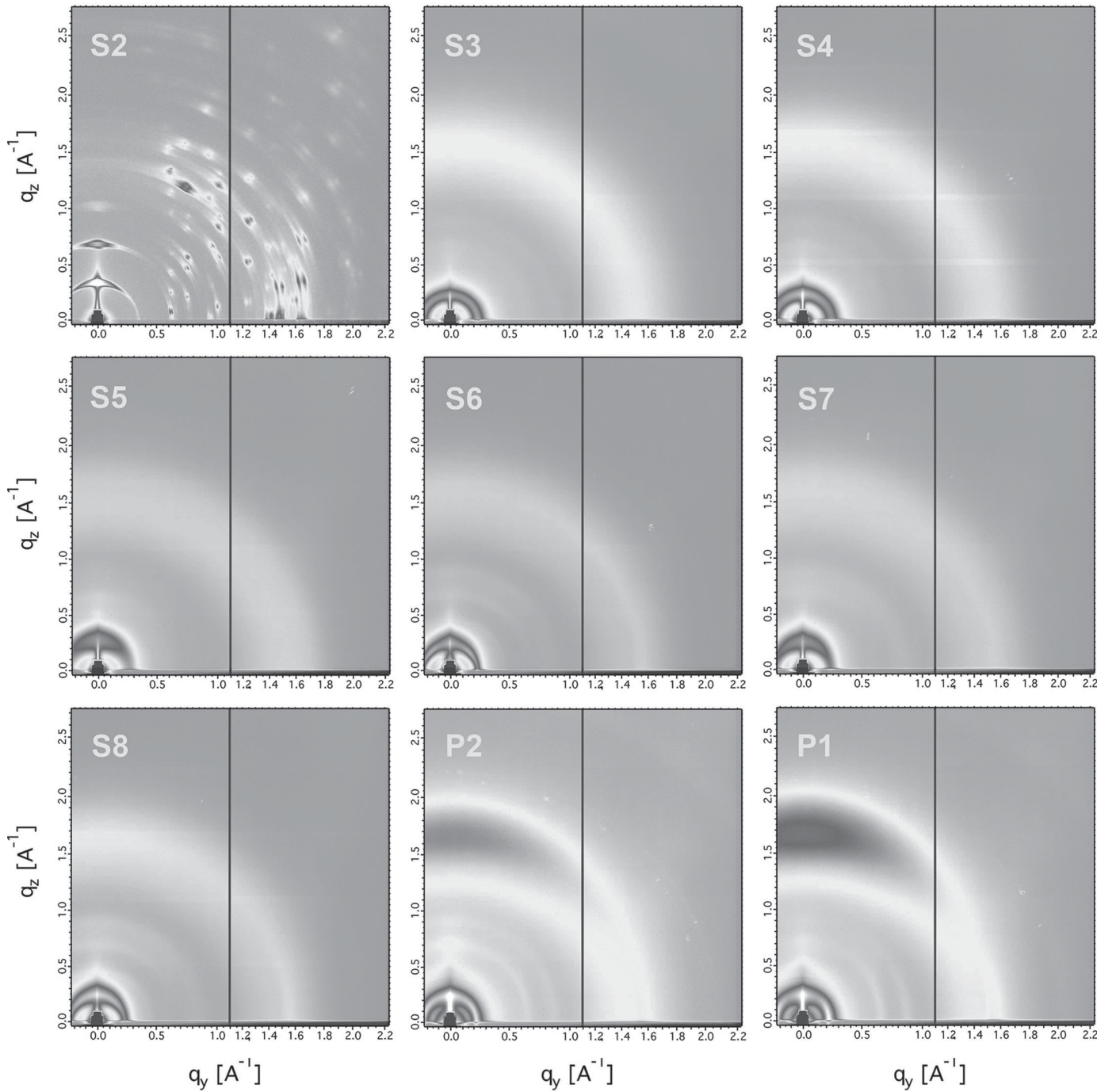

Figure 7. 2-D diffractograms of thin films of oligomers and polymers spun-cast from chloroform solution.
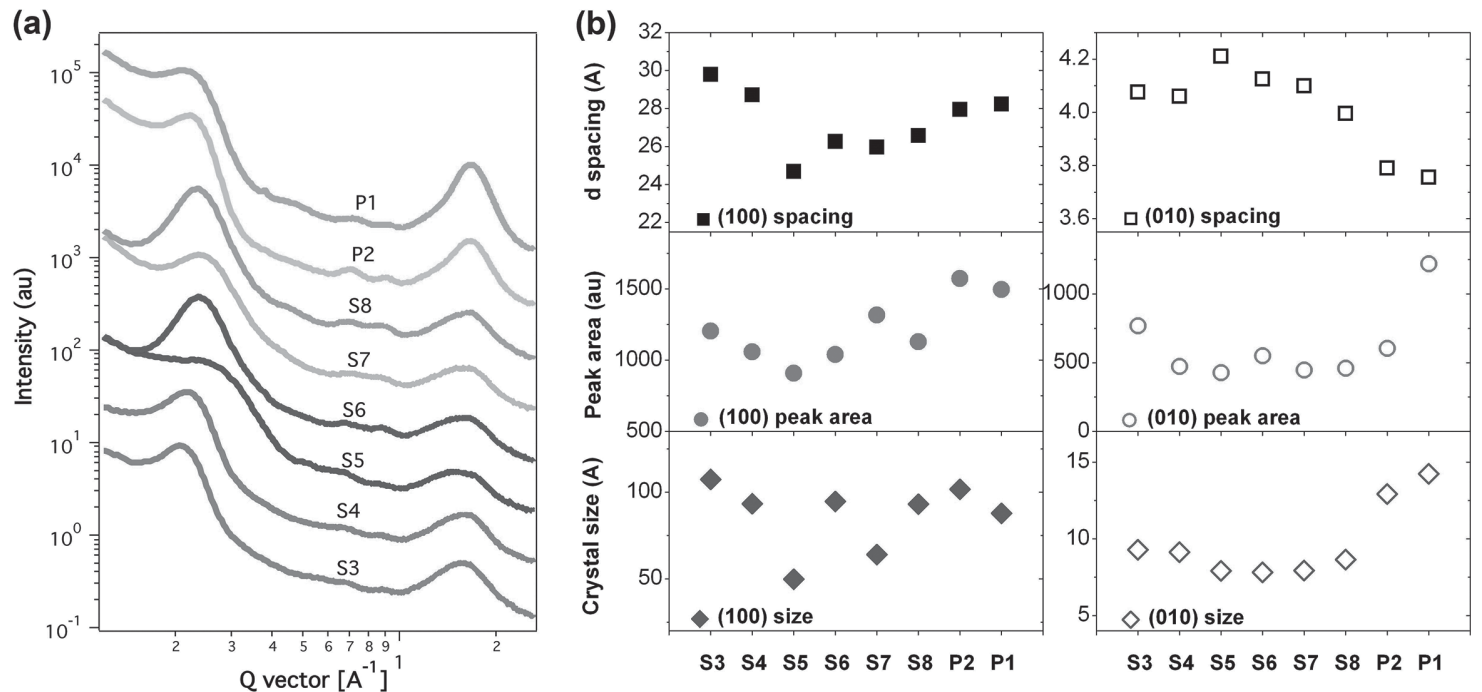

Figure 8. a) Out-of-plane line-cut profiles of oligomers and polymers in GIXD. b) Structure analysis. 


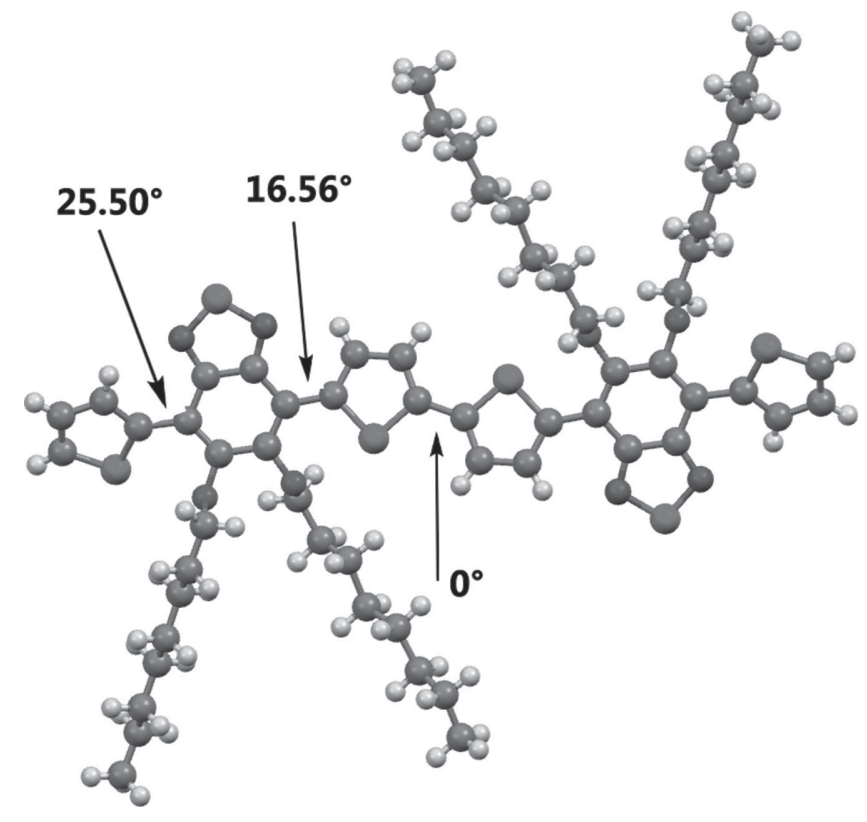

Figure 9. X-ray single-crystal structure of $\mathbf{S 2}$.

rings. An extended distance of $6.998 \AA$ for two adjacent molecule planes in the $\pi$-stacking direction and alkyl chains interpenetrating are found (CCDC 1007944).

\subsection{Photovoltaic Properties}

The photovoltaic properties of the oligomers and polymers were investigated on $\mathrm{BHJ}$ solar cells of inverted architecture of $16 \mathrm{~mm}^{2}$ active area using $\mathrm{PC}_{71} \mathrm{BM}$ as electron acceptor. The photoactive layer donor:acceptor with an optimal weight ratio of $1: 2$ was spin-cast on top of pre-fabricated $\mathrm{PF}_{3} \mathrm{~N}-\mathrm{OX}$ (poly[ $(9,9-$ bis (3'-(N,N-dimethylamino)propyl)-2,7-fluorene)-alt-2,7-(9,9bis(3-ethyl(oxetane-3-ethyloxy)-hexyl)-fluorene)]) layer from a 1:1 dichlorobenzene/chloroform solution. The active layer was heated at $80^{\circ} \mathrm{C}$ for $10 \mathrm{~min}$ to remove residual solvent before thermal evaporation of $\mathrm{MoO}_{3}$. The structure of the device was ITO/PF 3 N-OX/Active Layer/ $/ \mathrm{MoO}_{3} /$ Aluminium. ${ }^{[28]}$

Figure 10 shows the current density $(J)$ vs voltage $(V)$ of the cells under AM 1.5 simulated solar illumination while the corresponding data are listed in Table 2. As expected, the open-circuit voltage $\left(V_{\text {oc }}\right)$ decreases with the oxidation potential of the donor and hence from $\mathbf{S} 2$ to $\mathbf{S} 8$. The $J$ versus $V$ curves show that chain extension of the donor leads to an increase of the short-circuit current density $\left(U_{\mathrm{sc}}\right)$ from $\approx 3.00 \mathrm{~mA} \mathrm{~cm}^{-2}$ for $\mathbf{S} 3$ to $7.20-7.50 \mathrm{~mA} \mathrm{~cm}^{-2}$ for S6-S8. Combined with a gradual increase of the filling factor (FF) from 28 to $44 \%$, these results lead to an increase of PCE from 0.80 to $\approx 2.50 \%$. However, the cells based on the polymers show significantly better performances with $J_{\text {sc }}$ values $\approx 50 \%$ higher than those obtained with S6-S8 and improved FF leading to PCE of 3.75 and $4.40 \%$ for $\mathbf{P} 2$ and $\mathbf{P 1}$ respectively.

The external quantum efficiency (EQE) of the various cells under monochromatic light is shown in Figure 11. The spectrum of the cell based on $\mathbf{S} 2$ shows a broad response extending from 400 to $740 \mathrm{~nm}$ with a maximum of $\approx 20 \%$ at $470 \mathrm{~nm}$. This

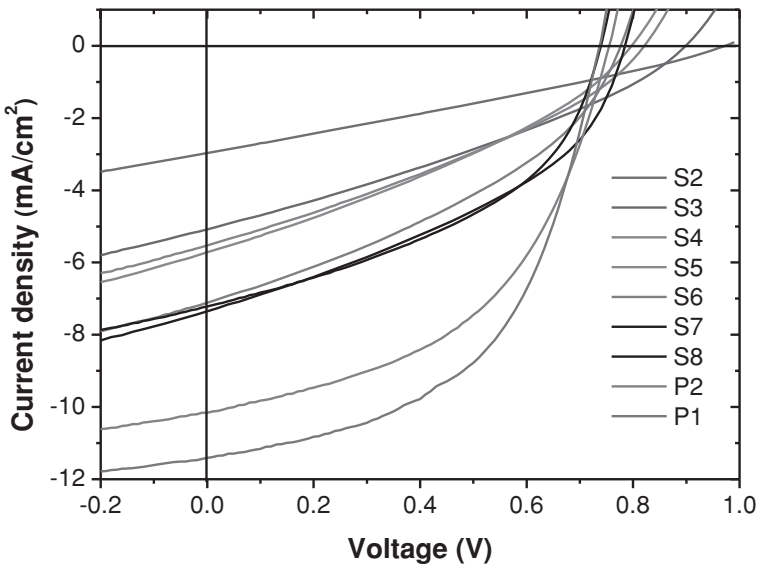

Figure 10. Current density vs voltage curves of the $\mathrm{BHJ}$ cells based on the oligomers and polymers under AM 1.5 simulated solar illumination with an incident power intensity of $100 \mathrm{~mW} \mathrm{~cm}$.

maximum clearly apparent in all EQE spectra corresponds to the contribution of $\mathrm{PC}_{71} \mathrm{BM}$ to the photocurrent. The spectrum exhibits a broad shoulder around $550 \mathrm{~nm}$ attributed to the red shifted absorption of $\mathbf{S 2}$ in the solid state while the $5-6 \%$ shoulder around $700 \mathrm{~nm}$ can be attributed to the aggregated phase. The spectra of the cells based on longer donors exhibit rather similar features with a progressive red-shift of the photo-response and increase of the photo-current. The cells based on S6, S7 and S8 give rather similar results with a broad maximum of $\approx 40 \%$ around $550 \mathrm{~nm}$ while the relative contribution of the absorption band associated with aggregation increases. Finally, the EQE spectra of the cells based on the polymers clearly show that in both cases a significant part of the photo-current is generated in the region corresponding to the aggregation band. These results agree well with the data obtained under white light illumination and confirm that the PV performances increase with the length of the donor but seem to converge toward a limit for systems donors containing 6-8 basic units. The performances of the cells based on the polymers clearly represent a qualitative jump with an increase of the maximum EQE from $40-45 \%$ for S6-S8 to $\approx 55 \%$ for P1 while the maximum EQE shifts bathochromically from 550 to

Table 2. Optimized OPV device parameters under AM 1.5 G illumination $\left(100 \mathrm{~mW} \mathrm{~cm}{ }^{-2}\right)$ and hole-mobilities measured on OFETs.

\begin{tabular}{lccccc}
\hline Donor & $\begin{array}{c}V_{\mathrm{oc}} \\
{[\mathrm{V}]}\end{array}$ & $\begin{array}{c}J_{\mathrm{sc}} \\
{\left[\mathrm{mA} \mathrm{cm}^{-2}\right]}\end{array}$ & $\begin{array}{c}\mathrm{FF} \\
{[\%]}\end{array}$ & $\begin{array}{c}\mathrm{PCE} \\
{[\%]}\end{array}$ & $\begin{array}{c}\mu_{\mathrm{h}} \\
{\left[\mathrm{cm}^{2} \mathrm{~V}^{-1} \mathrm{~s}^{-1}\right]}\end{array}$ \\
\hline S2 & 0.97 & 2.97 & 27.8 & $0.80[0.76]^{\mathrm{a})}$ & - \\
S3 & 0.90 & 5.09 & 31.4 & $1.44[1.32]$ & $2.19 \times 10^{-6}$ \\
S4 & 0.82 & 5.53 & 32.6 & $1.48[1.41]$ & $5.45 \times 10^{-5}$ \\
S5 & 0.80 & 5.71 & 32.7 & $1.50[1.43]$ & $3.85 \times 10^{-5}$ \\
S6 & 0.78 & 7.12 & 37.2 & $2.06[1.93]$ & $1.07 \times 10^{-5}$ \\
S7 & 0.78 & 7.34 & 40.2 & $2.30[2.24]$ & $2.65 \times 10^{-5}$ \\
S8 & 0.74 & 7.22 & 43.9 & $2.35[2.26]$ & $1.63 \times 10^{-5}$ \\
P2 & 0.76 & 10.16 & 48.5 & $3.75[3.54]$ & $4.56 \times 10^{-4}$ \\
P1 & 0.74 & 11.41 & 52.3 & $4.41[4.33]$ & $9.59 \times 10^{-4}$ \\
\hline
\end{tabular}

a) The values in brackets indicate the average values of PCEs. 


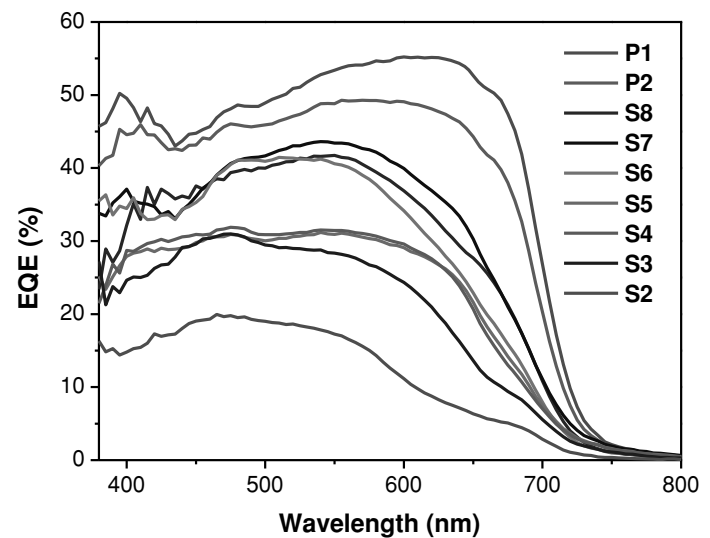

Figure 11. Spectra of external quantum efficiency for BHJ cells based on the oligomers and polymers as donor and $\mathrm{PC}_{71} \mathrm{BM}$ as acceptor.

$630 \mathrm{~nm}$. Comparison with the UV-Vis. absorption spectra of thin films (Figure S3c, SI) confirms that for the cells based on the longest oligomers and polymers, the maximum EQE is observed in the spectral range where absorption of the aggregated conjugated chains is predominant.

In order to complete these observations, the hole-mobility $\left(\mu_{\mathrm{h}}\right)$ of thin films of oligomers and polymers has been determined on top-contact organic field-effect transistors (OFETs) fabricated on n-doped silicon substrates with thermally grown $\mathrm{SiO}_{2}$ dielectric (see $\mathrm{SI}$ ).

As shown in Table 2, while oligomers $\mathbf{S 2 - S 8}$ show $\mu_{\mathrm{h}}$ values in the range of $10^{-5}-10^{-4} \mathrm{~cm}^{-2} \mathrm{~V}^{-1} \mathrm{~s}^{-1}$ with no clear correlation with chain-length, polymers $\mathbf{P} 2$ and especially $\mathbf{P} 1$ show much higher mobilities. These results suggest that the higher holemobility of the polymers contributes to the higher PCE of the polymer-based cells and in particular to the better FF values. In fact, a strong effect of the increase of hole-mobility on PCE independently of any other factors has been previously observed for molecular donors of a same series. ${ }^{[29]}$ Thus, although the longest oligomer S8 present a comparable molecular weight and even a slightly longer ECL than the polymer in solution, optical, structural and photovoltaic data provide convergent evidences indicating that in the solid-state, the stronger aggregation behavior of the polydisperse polymer is a key factor that leads to higher hole-mobility, bathochromically extended light-harvesting properties and thus higher PCE due to larger $J_{\mathrm{sc}}$ and FF. ${ }^{[30]}$

These results thus pose the problem of the role of polydispersity in the stronger ability of the polymer chains to aggregate. A first explanation would invoke the presence in the polymer of chains longer than the ECL of 7-8 units. Since the ECL is reached, UV-Vis absorption and photoluminescence spectra give no indication on this point, however, the GPC traces in Figure S2 (SI), suggest that the stronger propensity of P1 to aggregate is correlated with the presence of a large fraction of chains longer than the ECL represented by the GPC trace of S8. These longer chains, even if present in limited amounts, would act as glue for shorter chains. They serve as the morphology build framework, induce face-on orientation, reduce the $\pi-\pi$ stacking distance, and promote the photovoltaic performance. However a contribution of shorter oligomers in the overall aggregation process cannot be a priori excluded.

\section{Conclusion}

A series of well-defined hybrid donor-acceptor oligomers of a tricyclic system involving a benzothiadiazole acceptor block and two thiophene side units have been synthesized and the chain-length dependence of their electronic properties have been analyzed with reference to the corresponding polydisperse polymer. Optical data obtained in solution show that chain extension produces a red shift of $\lambda_{\max }$ and that highly extended oligomers can reach a longer $E C L$ than the polymer. UV-Vis absorption and photoluminescence results provide clear evidences for an increasing propensity for inter-chain aggregation probably enhanced by the D-A structure of the conjugated system. A chain length of 7-8 units, that is, 21-24 rings corresponds at the same time to the convergence limit of the optical HOMO-LUMO gap and to a turning point where the system evolves towards a polymer-like aggregation behavior. In the solid-state, the band gap of oligomers rapidly converges to the same value as the polymer. Electrochemical results on solid films suggest that this process is related to the rapid convergence of the valence band level due to inter-chain interactions.

GIXD investigations on films have shown that short-chain oligomers adopt an edge-on orientation evolving towards a more face-on orientation as chain length increases while the $\pi-\pi$ stacking distance gradually decreases after S7. The results obtained on BHJ solar cells show that, besides an expected decrease of $V_{\text {oc }}$, the lengthening of the donor chain leads to an increase of PCE with a convergence limit for 6-8 basic units, that is, the ECL of the system. However, the performances of the cells based on the polymers clearly evidence a further substantial increase of efficiency. Experimental results show that this phenomenon is due to the conjunction of several factors associated with aggregation namely improved light-harvesting properties, higher hole-mobility and better chain packing.

This work thus underlines the limits of the "classical" oligomer model and of the control of the HOMO-LUMO gap for the synthesis of OPV materials. This confirms that besides molecular engineering of the electronic properties, the structural control of inter-chains interactions and aggregation is one of the keys of the design of OPV materials based on linearly $\pi$-conjugated systems. On this basis, a possible direction for further work on monodisperse D-A oligomers as active OPV materials could focus on the structural control of enhanced intermolecular interactions of short-chain systems.

\section{Supporting Information}

Supporting Information is available from the Wiley Online Library or from the author. It contains experimental details of the synthesis of oligomers and polymers, instruments, measurements, and fabrication procedures and characterization details of the OPV and OFET devices.

\section{Acknowledgements}

This work was financially supported by the Ministry of Science and Technology (No. 2014CB643501), the Natural Science Foundation of China (Nos. 21125419 and 51361165301), Guangdong Natural Science 
Foundation (Grant No. S2012030006232) and Research Fund for the Doctoral Program of Higher Education of China (20120172140001). Morphological characterization of the materials was supported by Polymer-Based Materials for Harvesting Solar Energy (PHaSE), an Energy Frontier Research Center funded by the U.S. Department of Energy, Office of Basic Energy Sciences under award number DE-SC0001087. The authors acknowledge Dr. Ji-Jun Jiang (Sun Yat-Sen University) for crystal structure determination.

Received: June 13, 2014 Revised: August 29, 2014 Published online:

[1] a) G. Yu, J. Gao, J. C. Hummelen, F. Wudl, A. J. Heeger, Science 1995, 270, 1789; b) J. J. M. Halls, C. A. Walsh, N. C. Greenham, E. A. Marseglia, R. H. Friend, S. C. Moratti, A. B. Holmes, Nature 1995, 376, 498; c) C. J. Brabec, N. S. Sariciftci, J. C. Hummelen, Adv. Funct. Mater. 2001, 11, 15; d) Z. He, C. Zhong, X. Huang, W.-Y. Wong, H. Wu, L. Chen, S. Su, Y. Cao, Adv. Mater. 2011, 23, 4636

[2] a) B. C. Thompson, J. M. Frechet, Angew. Chem. Int. Ed. 2008, 47, 58; b) L. T. Dou, J. B. You, Z. R. Hong, Z. Xu, G. Li, R. A. Street, Y. Yang, Adv. Mater. 2013, 25, 6642; c) Y. J. He, Y. F. Li, Phys. Chem. Chem. Phys. 2011, 13, 1970

[3] a) D. Wöhrle, D. Meissner, Adv. Mater. 1991, 3, 129; b) N. S. Sariciftci, L. Smilowitz, A. J. Heeger, F. Wudl, Science 1992, 258, 1474; c) P. Sharma, K. Sreenivas, K. V. Rao, J. Appl. Phys. 2003, 93, 3963; d) A. Mishra, P. Bauerle, Angew. Chem. Int. Ed. 2012, 51, 2020

[4] a) Z. C. He, C. M. Zhong, S. J. Su, M. Xu, H. B. Wu, Y. Cao, Nat. Photonics 2012, 6, 591; b) J. You, L. Dou, K. Yoshimura, T. Kato, K. Ohya, T. Moriarty, K. Emery, C. C. Chen, J. Gao, G. Li, Y. Yang, Nat. Commun. 2013, 4, 1446; c) S. Liu, K. Zhang, J. Lu, J. Zhang, H.-L. Yip, F. Huang, Y. Cao, J. Am. Chem. Soc. 2013, 135, 15326.

[5] a) Y. F. Li, Acc. Chem. Res. 2012, 45, 723; b) C. Cui, W.-Y. Wong, Y. Li, Energy Environ. Sci. 2014, 7, 2276; c) Z. Liu, F. Xu, D. D. Yan, Acta Chim. Sin. 2014, 72, 171.

[6] W. Li, L. Yang, J. R. Tumbleston, L. Yan, H. Ade, W. You, Adv Mater 2014, 26, 4456

[7] a) J. Roncali, Acc. Chem. Res. 2009, 42, 1719; b) Y. W. Li, Q. Guo, Z. F. Li, J. N. Pei, W. J. Tian, Energy Environ. Sci. 2010, 3, 1427; c) B. Walker, C. Kim, T.-Q. Nguyen, Chem. Mater. 2010, 23, 470; d) Y. Z. Lin, Y. F. Li, X. W. Zhan, Chem. Soc. Rev. 2012, 41, 4245

[8] a) J. Y. Zhou, Y. Zuo, X. J. Wan, G. K. Long, Q. Zhang, W. Ni, Y. S. Liu, Z. Li, G. R. He, C. X. Li, B. Kan, M. M. Li, Y. S. Chen, J. Am. Chem. Soc. 2013, 135, 8484; b) A. K. K. Kyaw, D. H. Wang, D. Wynands, J. Zhang, T. Q. Nguyen, G. C. Bazan, A. J. Heeger, Nano Lett. 2013, 13, 3796.

[9] a) J. S. Sears, R. R. Chance, J.-L. Bredas, J. Am. Chem. Soc. 2010, 132, 13313; b) J. L. Bredas, J. Cornil, D. Beljonne, D. dos Santos, Z. G. Shuai, Acc. Chem. Res. 1999, 32, 267; c) P. Brocorens, E. Zojer, J. Cornil, Z. Shuai, G. Leising, K. Mullen, J. L. Bredas, Synth. Met. 1999, 100, 141; d) H. Meier, U. Stalmach, H. Kolshorn, Acta Polym. 1997, 48, 379; e) R. E. Martin, F. Diederich, Angew. Chem. Int. Ed. $1999,38,1350$

[10] a) R. Schenk, H. Gregorius, K. Meerholz, J. Heinze, K. Muellen, J. Am. Chem. Soc. 1991, 113, 2634; b) J. A. He, J. L. Crase, S. H. Wadumethrige, K. Thakur, L. Dai, S. Z. Zou, R. Rathore, C. S. Hartley, J. Am. Chem. Soc. 2010, 132, 13848.

[11] H. Meier, J. Gerold, H. Kolshorn, W. Baumann, M. Bletz, Angew. Chem. Int. Edit. 2001, 41, 292.

[12] a) P. Bauerle, T. Fischer, B. Bidlingmeier, A. Stabel, J. P. Rabe, Angew. Chem. Int. Ed. 1995, 34, 303; b) G. Bidan, A. De Nicola, V. Enee, S. Guillerez, Chem. Mater. 1998, 10, 1052; c) T. Izumi,
S. Kobashi, K. Takimiya, Y. Aso, T. Otsubo, J. Am. Chem. Soc. 2003, 125, 5286.

[13] J. Gierschner, J. Cornil, H. J. Egelhaaf, Adv. Mater. 2007, 19, 173.

[14] L. Zhang, N. S. Colella, F. Liu, S. Trahan, J. K. Baral, H. H. Winter, S. C. Mannsfeld, A. L. Briseno, J. Am. Chem. Soc. 2013, 135, 844.

[15] a) E. H. Elandaloussi, P. Frere, P. Richomme, J. Orduna, J. Garin, J. Roncali, J. Am. Chem. Soc. 1997, 119, 10774; b) I. Jestin, P. Frere, N. Mercier, E. Levillain, D. Stievenard, J. Roncali, J. Am. Chem. Soc. 1998, 120, 8150; c) J. Roncali, Acc. Chem. Res. 2000, 33, 147.

[16] a) Y. H. Geng, A. Trajkovska, D. Katsis, J. J. Ou, S. W. Culligan, S. H. Chen, J. Am. Chem. Soc. 2002, 124, 8337; b) Q. L. Wang, Y. Qu, H. K. Tian, Y. H. Geng, F. S. Wang, Macromolecules 2011, 44, 1256.

[17] J. H. Jo, C. Y. Chi, S. Hoger, G. Wegner, D. Y. Yoon, Chem-Eur. J. 2004, 10, 2681.

[18] a) Y. J. Cheng, S. H. Yang, C. S. Hsu, Chem. Rev. 2009, 109, 5868; b) J. Chen, Y. Cao, Acc. Chem. Res. 2009, 42, 1709; c) Y. Liang, L. Yu, Acc. Chem. Res. 2010, 43, 1227; d) P.-L. T. Boudreault, A. Najari, M. Leclerc, Chem. Mater. 2010, 23, 456; e) L. J. Huo, S. Q. Zhang, X. Guo, F. Xu, Y. F. Li, J. H. Hou, Angew. Chem. Int. Ed. 2011, 50, 9697.

[19] a) X. Liu, Y. Sun, L. A. Perez, W. Wen, M. F. Toney, A. J. Heeger, G. C. Bazan, J. Am. Chem. Soc. 2012, 134, 20609; b) X. Liu, Y. Sun, B. B. Y. Hsu, A. Lorbach, L. Qi, A. J. Heeger, G. C. Bazan, J. Am. Chem. Soc. 2014, 136, 5697; c) J. Liu, Y. Sun, P. Moonsin, M. Kuik, C. M. Proctor, J. Lin, B. B. Hsu, V. Promarak, A. J. Heeger, T.-Q. Nguyen, Adv. Mater. 2013, 25, 5898; d) M. Melucci, L. Favaretto, A. Zanelli, M. Cavallini, A. Bongini, P. Maccagnani, P. Ostojo, G. Derue, R. Lazzaroni, G. Barbarello, Adv. Funct. Mater. 2010, 20, 445

[20] a) S. S. Zade, N. Zamoshchik, M. Bendikov, Acc. Chem. Res. 2011, 44, 14; b) W. Li, K. H. Hendriks, A. Furlan, W. S. C. Roelofs, S. C. J. Meskers, M. M. Wienk, R. A. J. Janssen, Adv. Mater. 2014, 26, 1565; c) F. P. V. Koch, M. Heeney, P. Smith, J. Am. Chem. Soc. 2013, 135, 13699.

[21] a) M. Helgesen, S. A. Gevorgyan, F. C. Krebs, R. A. J. Janssen, Chem. Mater. 2009, 21, 4669; b) P. Ding, C. C. Chu, B. Liu, B. Peng, Y. P. Zou, Y. H. He, K. C. Zhou, C. S. Hsu, Macromol. Chem. Phys. 2010, 211, 2555

[22] R. C. Coffin, J. Peet, J. Rogers, G. C. Bazan, Nat. Chem. 2009, 1, 657.

[23] a) F. Wurthner, C. Thalacker, S. Diele, C. Tschierske, Chem. Eur. J. 2001, 7, 2245; b) S. Ghosh, X.-Q. Li, V. Stepanenko, F. Wuerthner, Chem. Eur. J. 2008, 14, 11343

[24] J. Roncali, Chem. Rev. 1997, 97, 173.

[25] U. Lemmer, S. Heun, R. F. Mahrt, U. Scherf, M. Hopmeier, U. Siegner, E. O. Göbel, K. Müllen, H. Bässler, Chem. Phys. Lett. 1995, 240, 373.

[26] K. Takimiya, I. Osaka, M. Nakano, Chem. Mater. 2014, 26, 587.

[27] a) J. Rivnay, S. C. B. Mannsfeld, C. E. Miller, A. Salleo, M. F. Toney, Chem. Rev. 2012, 112, 5488; b) F. Liu, Y. Gu, X. Shen, S. Ferdous, H.-W. Wang, T. P. Russell, Prog. Polym. Sci. 2013, 38, 1990; c) W. Chen, T. Xu, F. He, W. Wang, C. Wang, J. Strzalka, Y. Liu, J. Wen, D. J. Miller, J. Chen, K. Hong, L. Yu, S. B. Darling, Nano Lett. 2011, 11, 3707.

[28] a) Y. Dong, X. Hu, C. Duan, P. Liu, S. Liu, L. Lan, D. Chen, L. Ying, S. Su, X. Gong, F. Huang, Y. Cao, Adv. Mater. 2013, 25, 3683; b) K. Zhang, X. Guan, F. Huang, Y. Cao, Acta Chim. Sin. 2012, 70, 2489 .

[29] T. Rousseau, A. Cravino, E. Ripaud, P. Leriche, S. Rihn, A. De Nicola, R. Ziessel, J. Roncali, Chem. Commun. 2010, 46, 5082.

[30] R. Noriega, J. Rivnay, K. Vandewal, F. P. V. Koch, N. Stingelin, P. Smith, M. F. Toney, A. Salleo, Nat. Mater. 2013, 12, 1037. 